\title{
An Internet-Based Consumer Resource for People with Low Back Pain (MyBackPain): Development and Evaluation
}

Paul William Hodges, BPhty (Hons), PhD, MedDr, DSc; Jenny Setchell, PhD, BPhty; Mandy Nielsen, PhD, BSocW The University of Queensland, Brisbane, Australia

Corresponding Author:

Paul William Hodges, BPhty (Hons), PhD, MedDr, DSc

The University of Queensland

School of Health and Rehabilitation Sciences

Brisbane, 4072

Australia

Phone: 61404854589

Email: p.hodges@uq.edu.au

\section{Abstract}

People increasingly use the internet to obtain information about health complaints, including low back pain (LBP). LBP is the leading cause of disability internationally, and outcomes are worsening. There is an urgent need for resources that aid improvement of outcomes. There have been calls to engage consumers in the development of resources, but this has rarely been implemented. MyBackPain is a website that was developed with extensive involvement of consumers to ensure that the resource meets their needs for content and presentation. This paper aimed to describe the multistep process undertaken to develop the MyBackPain website and provide an extensive evaluation of its impact. Development of MyBackPain involved 10 steps, many of which have been published in the academic literature. These steps included consultation regarding consumer needs, evaluation of existing internet resources, identification of key messages to be reinforced, identification of frequently asked questions, consensus for content, content development (including development of algorithms to guide tailoring of the user experience), development of consumer-focused evidence-based treatment summaries, development of descriptions of health care providers, and testing. Evaluation included qualitative examination of people's interactions with the website and its effects on their daily lives and an ongoing randomized controlled trial of impact of use of the site on people's LBP-related health literacy, clinical outcomes, and treatment choices. It is hoped that the website can aid in the reduction of the massive burden of LBP and provide a template for the development of resources for other conditions.

(JMIR Rehabil Assist Technol 2020;7(1):e16101) doi: 10.2196/16101

\section{KEYWORDS}

back pain; patient education; patient internet portals; evidence-based health care; patient involvement; service user involvement

\section{Introduction}

\section{Background}

The most recent global burden of disease study confirmed that low back pain (LBP) is the leading cause of disability worldwide [1], with enormous individual and economic burden. LBP accounts for $30 \%$ of all chronic pain [2] and affects up to $80 \%$ of individuals at least once in their life [3]. Unnecessary and ineffective assessments and/or treatments and poor quality management contribute to much of this burden [4]. Although negative messages and beliefs can lead to worse outcomes [5], beliefs about LBP can be positively affected by evidence-based information [6,7]. Furthermore, empowering patients to make informed choices can assist them to engage successfully with health advice and reduce care needs [8]. Early education and access to the most effective treatments could reduce the excessive burden of LBP. This understanding provides a foundation for a resource for people with LBP to provide accurate information about their condition, to empower them to actively participate in managing it, to navigate treatments, and to understand the roles of different health care providers.

Despite clear clinical guidelines, research of primary care physicians indicates that most individuals with LBP do not receive evidence-based care [4] and best possible outcomes are not being achieved [4]. For instance, contrary to guideline recommendations, more than $25 \%$ of patients are referred for imaging [4] and less than approximately $20 \%$ of patients with new LBP receive advice and education, although this is universally recommended in guidelines [4]. Of particular concern is the fact that $20 \%$ of patients with LBP are 
inappropriately prescribed opioids [4]. This research strongly suggests a gap in translating identified best practice and disseminating evidence-based LBP information.

People increasingly use the internet to obtain information related to health conditions $[9,10]$. The capacity of the internet to provide tailored information in varied formats at a time and place of the user's choosing makes it an ideal platform to educate and engage people with LBP in the management of their condition. Notably, people with LBP consistently express a desire for trustworthy information about their condition [11-14]. Internet-based resources could enable patients to become better informed about their condition and treatment options [15-18] to improve outcomes and guide appropriate use of health resources [16,19,20]. Enhanced health literacy as a consequence of access to high-quality internet resources could also lead to efficient use of clinical consultation time [17,19], enhance relationships between patients and clinicians [16], and shared decision making [19].

Unfortunately, most websites about LBP provide inaccurate information [21] and are consistently rated as poor in overall quality when evaluated against criteria developed from relevant guidelines and research [22-24]. Furthermore, the criteria used to evaluate websites have largely been based on perspectives of researchers or clinicians [24-26], with a foundation in traditional literature [22,27] or clinical practice guidelines [22,23], and have not considered patient perspectives [28]. There is increasing emphasis placed on consideration of perspectives and preferences of people with a condition [29]. Furthermore, the relevance and accessibility of material are improved by involvement of consumers in the development of health information resources [30]. Despite repeated recommendations for consumer involvement in the preparation of educational resources [31], there has been limited attention to consumers' views regarding content and presentation [15,26,32-34].

\section{Objectives}

This paper describes the process undertaken to develop a consumer-focused internet-based resource for individuals with LBP and the evaluation of its impact. Here, we describe the multistep process undertaken to develop the resource, with specific emphasis on the engagement of consumers, clinicians, and experts at each step, and the plan and preliminary outcomes from analysis of impact.

\section{Methods and Results}

\section{Overview of Website Development}

The overall objective of the development of the internet resource for individuals with LBP was to provide high-quality, evidence-based resources that would meet the needs of consumers in terms of content and presentation. The overarching strategy was devised a priori and was planned to involve input from people with the condition (experts by experience), clinicians, experts from multiple disciplines, and professional societies at multiple time points (Figure 1). A series of research studies with qualitative and quantitative components were undertaken to inform the development and ensure the resource met the objectives.

\section{Development of an Internet Resource for People With Low Back Pain}

\section{Step 1. Identification of Consumer Needs-Website Content and Presentation}

The first step in the development of the website was to undertake 2 qualitative studies to identify the needs of people with LBP in terms of content and presentation. These studies involved focus groups and interviews with people with LBP [35] and health care providers from multiple disciplines [36]. Data were analyzed thematically and used to generate a list of 12 content areas and 4 presentation preferences (an adapted version from Nielsen et al. [35] is presented in Textbox 1). Although people with LBP and health care providers agreed in most content areas, there were some differences. For instance, consumers wanted more specific explanation of diagnoses and treatments than the health care providers deemed possible or comfortable to provide on a website. Consumers also wanted capacity for consumer-to-consumer interaction in online forums, whereas health care providers express concerns that patient experiences may reinforce inappropriate messages. We deemed it too early to implement an online support group, and we have recently undertaken a systematic review (Maclachlan L, Mills K, Lawford BJ, Egerton T, Setchell J, Hall LM, Plinsinga ML, Besomi M, Teo PL, Eyles J, Mellor R, Hodges P, Hunter DJ, Vicenzino B, Bennell K, unpublished data, November 2019) and survey of views of individuals with musculoskeletal conditions [37] regarding online support groups as preliminary steps toward developing this component. 
Figure 1. Steps undertaken for the development of the MyBackPain website. Involvement of consumers, health care providers, and experts is identified for relevant steps. LBP: low back pain.

Involvement of health care
providers and/or experts

Focus group of health care

providers

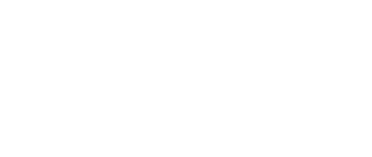

Delphi process for consensus on messages; online ranking process to identify priority messages

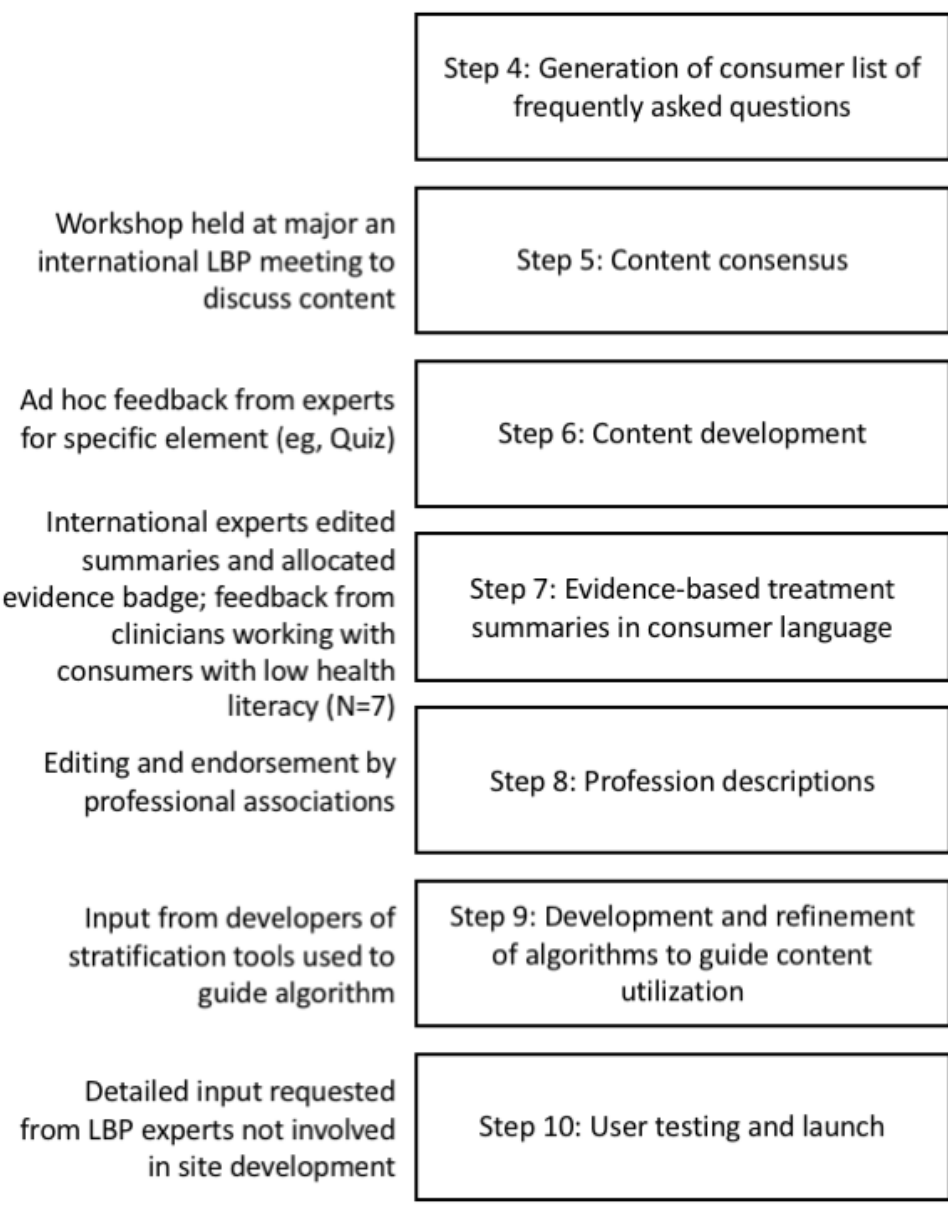

Step 2: Evaluation of existing LBP
Involvement of people with LBP (consumers)

\section{Step 1: Identification of consumer needs} websites
Focus group of consumers to identify needs

Evaluation against criteria based on consumer view (step 1)

Focus group of consumers to refine language; online ranking process to identify priority messages

Focus group of consumers to identify questions they want answered

Editing by a consumer writer; ad hoc feedback from people with LBP as required

Feedback provided for each treatment summary by people with LBP $(\mathrm{N}=28)$

Prepared and edited by a consumer writer

Detailed evaluation of use and interpretation by people with LBP $(\mathrm{N}=10)$ 
Textbox 1. Consumer preferences for website content and presentation.

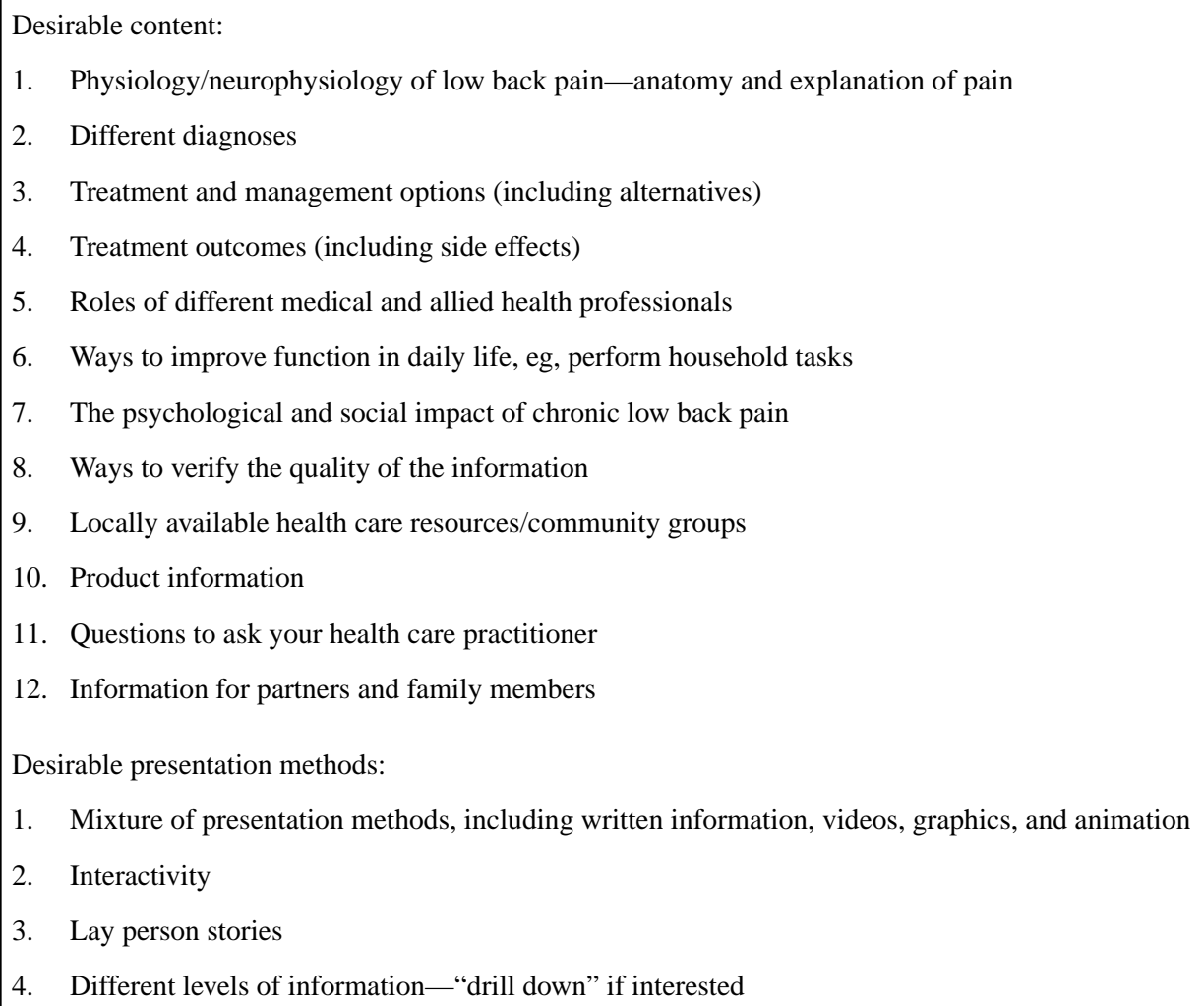

\section{Step 2. Evaluation of Existing Low Back Pain Websites}

To determine the need for the potential resource, a review was undertaken to determine whether current websites already met consumer needs for content and presentation [38]. This review was undertaken at 3 different time points (2010, 2015, and 2019; to determine whether resources were changing over time) and involved virtual searches using Internet Protocol addresses from different countries (Australia, the United Kingdom, and the United States; to determine whether alignment of website content and presentation was better in some locations than others). All websites were evaluated against a 16-item checklist (12 content items and 4 presentation items) developed from the consumer preferences identified in step 1 [38]. The review identified that existing websites were poorly aligned with patient preferences, that this was not improving (or was even getting worse) over time, and did not differ between locations of the internet search. In 2010, no website was scored as excellent, and $58 \%$ scored as poor or fair. Key areas in which websites did not meet consumer needs were as follows: less than $50 \%$ of websites included information on treatment outcomes or information on psychological and social impact of chronic pain, less than $20 \%$ of websites included information regarding health care provider roles or questions to ask health care practitioners, and none of the websites included information for family and friends. On the basis of this review, it was deemed necessary to begin building a consumer-focused internet resource for people with LBP.

\section{Step 3. Identification of Key Messages}

In step 1, consumers and health care providers had expressed a clear preference for access to evidence-based information about multiple aspects of LBP. Although evidence for treatments and diagnostic procedures are frequently the subject of systematic reviews and meta-analysis, other aspects of advice and education are infrequently considered in this robust manner. As a result, we sought to identify and reach expert consensus on a list of evidence-based messages that should be reinforced frequently and consistently in various formats (eg, patient narratives and information sheets) in a website [39]. For this step, evidence-based messages were first identified from the literature (clinical practice guidelines and systematic reviews, eg, the study by Koes et al [40]), which produced a provisional list of 44 messages. Second, a multidisciplinary panel of experts and patients with LBP were consulted using a Delphi process to review, to add to, and to refine the key messages. Third, using consumer focus groups and a consumer writer, messages were refined and language was optimized to ensure messages were understandable and nonambiguous to people with LBP. This process resulted in a final list of 30 key messages that were categorized into 6 major thematic areas: principles of management, reassurance, staying active, unnecessary interventions, red flags, and disease knowledge (Table 1). 
Table 1. Key messages identified for reinforcement throughout the website.

\begin{tabular}{|c|c|c|}
\hline Thematic area and key message & Expert rank & Patient rank \\
\hline \multicolumn{3}{|l|}{ Stay active } \\
\hline Bed rest for more than a day or two is not good & 14 & 22 \\
\hline Do not take back pain lying down & 19 & 25 \\
\hline Staying active helps prevent long-term back problems & 5 & 8 \\
\hline When you have back pain, carry on with normal activities as far as possible & 2 & 24 \\
\hline When you have back pain, staying active is important. You need to pace yourself to return to your usual activities & 1 & 5 \\
\hline \multicolumn{3}{|l|}{ Unnecessary investigations } \\
\hline Blood tests are usually not needed in the majority of cases of $\mathrm{LBP}^{\mathrm{a}}$ & 29 & 28 \\
\hline $\begin{array}{l}\mathrm{CT}^{\mathrm{b}} \text { scans have little use in diagnosing back problems, and caution should be exercised because of the large amount } \\
\text { of radiation involved with their use }\end{array}$ & 22 & 30 \\
\hline $\begin{array}{l}\text { Imaging (eg, } \mathrm{x} \text {-ray, CT scan, or magnetic resonance imaging) is usually not needed in the majority of cases of LBP, } \\
\text { particularly when your pain has been present for less than } 6 \text { weeks. Talk to your doctor about this }\end{array}$ & 10 & 21 \\
\hline X-rays will not highlight the cause of pain in most cases, unless a fracture is suspected & 12 & 27 \\
\hline \multicolumn{3}{|l|}{ Principles Mx $\mathbf{c}^{\mathbf{c}}$} \\
\hline Health practitioners can assist in screening for causes of back pain & 30 & 15 \\
\hline $\begin{array}{l}\text { If you have any further questions to ask your health practitioner, write them down and discuss them at your next } \\
\text { visit }\end{array}$ & 28 & 9 \\
\hline $\begin{array}{l}\text { Persistent LBP is influenced by a number of factors-physical, emotional, and environmental; it is important to } \\
\text { address each of these areas }\end{array}$ & 18 & 6 \\
\hline Staying positive is important. Help is available & 21 & 13 \\
\hline Take ownership of your own well-being & 20 & 20 \\
\hline Work toward returning to your usual activities, with guidance from your health practitioner & 16 & 7 \\
\hline Work with your health practitioner to address your concerns & 26 & 10 \\
\hline Work with your health practitioners to manage your back pain & 27 & 11 \\
\hline Work with your health care team to set goals & 25 & 16 \\
\hline \multicolumn{3}{|l|}{ Disease knowledge } \\
\hline In around $95 \%$ of cases, it is not possible to pinpoint the cause of back pain & 23 & 29 \\
\hline LBP may happen again over time & 24 & 19 \\
\hline \multicolumn{3}{|l|}{ Reassurance } \\
\hline $\begin{array}{l}\text { In most cases of recent onset back pain, the pain will get better in several weeks; however, this varies from person } \\
\text { to person }\end{array}$ & 7 & 14 \\
\hline It is normal to worry about the cause of your back pain and the impact it may have on you & 17 & 12 \\
\hline It is not necessary to know the specific cause of your back pain to manage the pain effectively & 13 & 23 \\
\hline It is rare for LBP to be caused by a more serious health problem & 9 & 26 \\
\hline $\begin{array}{l}\text { Most people find that their back pain settles down over a short period of time. If your back pain persists and is } \\
\text { worrying you, consult a health professional }\end{array}$ & 6 & 4 \\
\hline Most people have pain in their low back at some stage in their lives & 11 & 18 \\
\hline $\begin{array}{l}\text { Your pain may not necessarily be related to the extent of damage in your back. Hurt does not necessarily mean } \\
\text { harm }\end{array}$ & 3 & 17 \\
\hline \multicolumn{3}{|l|}{ Red flag } \\
\hline $\begin{array}{l}\text { You should see a health practitioner if you have back pain and any of the following: pain that spreads down } 1 \text { or } \\
\text { both legs: a fever, recent invasive procedure (eg, surgery), recent significant trauma, unexplained weight loss, and } \\
\text { history of cancer }\end{array}$ & 8 & 3 \\
\hline $\begin{array}{l}\text { You should see a health practitioner urgently if you have back pain and either of the following: bladder and/or } \\
\text { bowel disturbance or significant leg muscle weakness }\end{array}$ & 4 & 1 \\
\hline
\end{tabular}




\begin{tabular}{|c|c|c|}
\hline Thematic area and key message & Expert rank & Patient rank \\
\hline $\begin{array}{l}\text { You should see your health practitioner if your back pain is severe and it is worrying you, if you are having diffi- } \\
\text { culty managing your back pain, or if your pain is getting worse }\end{array}$ & 15 & 2 \\
\hline
\end{tabular}

${ }^{a}$ LBP: low back pain.

${ }^{\mathrm{b}} \mathrm{CT}$ : computerized tomography.

${ }^{\mathrm{c}} \mathrm{Mx}$ : management.

Once developed, the list of key messages was subjected to 2 additional analyses. First, 2 groups (people with LBP and multidisciplinary international LBP experts) were asked to rank the messages in terms of their perceived priority or importance using an online process. This process highlighted some similarities in order of importance expressed by these 2 groups (eg, both groups prioritized messages related to identification of red flags to recommend the seeking of advice from a health care provider) but also some major differences. For instance, people with LBP prioritized messages about management strategies and ranked advice to avoid unnecessary investigations very low, whereas health care providers prioritized advice to stay active and reassurance. Contrasting views of experts and consumers were not unexpected but highlighted that care would be required to ensure patients were engaged with the website (eg, access to the information they wanted), and they were also guided to advice that may be contrary to their desires/beliefs (eg, patients continue to demand investigations despite evidence that they are only indicated in a small proportion of cases and evidence that early imaging can increase disability and duration of LBP [41]).

Second, developers of clinical practice guidelines that were published after the preparation of the list of key messages were surveyed using a Delphi method to ascertain whether messages remained consistent with newly developed guidelines. All messages were endorsed using this process.

\section{Step 4. Generation of Consumer List of Frequently Asked Questions}

In parallel with the development of a list of evidence-based key messages, a qualitative study with focus groups of people with LBP was undertaken to identify a provisional list of questions that consumers would like to have answered with an education resource (Nielsen M, Hodges PW, unpublished data January 2017). Thematic analysis of the focus groups provided an initial list of "frequently asked questions" (FAQs) to serve as a starting point for FAQs to be added to the site during development.

\section{Step 5. Content Consensus}

After establishing the needs of consumers and confirmation that a new resource was needed to meet these needs (described above), we held a workshop at the 13th International Back and
Neck Pain Research Forum in Campos do Jordao, Brazil, to generate expert consensus on the plans for content of the website. At the workshop, participants endorsed the findings of the prior steps, and it was agreed that the website should aim to improve health outcomes for individuals with LBP by (1) enhancing the confidence of individuals with LBP to manage their condition and make evidence-based treatment choices and to avoid ineffective, unnecessary, and potentially harmful investigations and treatments; (2) demedicalizing and normalizing LBP with messages in multiple formats that reinforce that LBP is a natural part of life for many and in most cases can be managed with early return to activity; (3) providing tools for individuals to identify whether further investigation and/or management may be required; and (4) engaging patients in healthy behaviors and attitudes about LBP. These objectives of the website were used to underpin the development of the content in step 6.

\section{Step 6. Content Development}

Using the outcomes from steps 1 to 5 as a starting point, an extensive process of content development was undertaken with leadership by a postdoctoral research fellow (background in physiotherapy and psychology), an international multidisciplinary steering committee, and a consumer writer. A partnership was developed with Arthritis Australia, which is a charitable, not-for-profit organization and the peak arthritis consumer body in Australia, to host the site and aid in the development of specific areas of content (eg, preparation of videos).

Table 2 presents the final list of content areas and the intended purpose of each. Content was developed using varying methods and consultations according to nine key principles: (1) written in consumer language, (2) evidence based, (3) bio-psycho-social underpinning, (4) aligned with key messages, (5) no commercial goal, (6) no single professional affiliation/bias, (7) focus on empowerment of patient to take control of their LBP, (8) focus on reassurance and informed choices, and (9) using a design that would be engaging for users (contemporary, interactive, and intuitive). Content presentation methods were aligned with the preferences of consumers identified in step 1. Development of content for several areas required a more detailed process and are described separately in steps 7 to 9 . 
Table 2. Final content developed for MyBackPain website.

\begin{tabular}{ll}
\hline Content area & Purpose \\
\hline Guide me & $\begin{array}{l}\text { Provide tailored guidance regarding prognosis and recommended resources based on responses to questions based } \\
\text { on } 2 \text { evidence-based prognostic tools }\end{array}$
\end{tabular}

\section{Back pain information}

About back pain

Do it yourself

Treatments

Health care professionals

Test your knowledge

For family and friends

\section{Videos}

Back pain information

Living well with back

pain-people's stories

Frequently asked questions

What can I do to help my

LBP?

Back pain causes

What is going to happen?

Seeking help

About us

\section{Other features}

Daily/weekly healthy messages by email
General information regarding back pain with emphasis on reassurance and bio-psycho-social model of pain

Summary of useful tips to help people with LBP to do the things they want/need to do. Also link to other online self-help tools (eg, Paintrainer program to learn pain coping skills)

Evidence-based summaries of 80 common treatments for LBP in consumer-friendly language. Evidence badges to provide quick reference of efficacy of intervention. Information of how to prepare for a consultation with a health care professional and questions to ask

Description of health care professionals who commonly manage LBP and how to find them

Quiz to test knowledge about LBP that addresses main key messages and common myths about LBP

Guide to information for family and friends to understand LBP and provide support

Library of videos designed to provide narratives that reinforce key messages

Stories of people who are living with LBP

Key questions identified by consumers as issues they want to understand better

Response to questions related to self-management

Responses to questions related to back pain causes

Responses to questions regarding prognosis and other requests

Responses to general questions regarding health professionals

Information regarding the developers and funders of the MyBackPain website

${ }^{\mathrm{a}}$ LBP: low back pain.

\section{Step 7. Evidence-Based Treatment Summaries in Consumer Language}

Orthodox and complimentary treatments commonly used by people with LBP were identified by the expert steering committee with consumer input. The committee agreed upon a final list of 80 treatments grouped into 16 broad areas (Table 2). An independent expert group (International Centre for Allied Health Evidence, University of South Australia, Adelaide, Australia) was contracted to develop a draft description of each treatment, and a synthesis of research evidence was prepared from the best available evidence (systematic reviews, clinical trials, and clinical practice guidelines). Draft descriptions were edited for language by a consumer writer. For each treatment, information was provided regarding (1) basic description (what is it?, how does it work?, and is it effective for treating back pain?), (2) detailed treatment information, (3) points to consider (defined as "pluses" and "minuses"), (4) FAQs, and (5) key references. A series of "evidence grade badges" was developed by the expert steering committee with consultation with external experts in evidence-based practice and a consumer writer (Figure 2 ). Evidence grades aimed to enable quick identification of evidence levels for treatments or the potential for harm and were also designed not to overemphasize scientific evidence (or lack of) as the only source of information that might be of value to consumers. International experts in each type of treatment (including a senior and early career researcher where possible) were identified by the expert steering committee to review each treatment summary and allocate an "evidence grade badge." All summaries and evidence grades were reviewed for consistency by the steering committee and 3 additional experts over a series of teleconferences. After completion of the 80 treatment summaries, 28 individuals with LBP were recruited to provide detailed review of 2 to 3 treatment summaries each to provide feedback of content and language. We also garnered feedback from 7 clinicians working with people likely to have low health literacy. 
Figure 2. Evidence grading badges developed to enable identification of evidence levels for treatments or the potential for harm.

\section{GOOD EVIDENCE}

MAY WORK

MAY BE HARMFUL

UNLIKLEY TO WORK

\section{NOT ENOUGH EVIDENCE}

These treatments are useful. They are supported by scientific evidence as effective. The benefits outweigh the risks.

\author{
These treatments are promising and may be \\ useful. They have some evidence to support \\ them, but more evidence is needed to be sure \\ they work. It is likely that benefits outweigh the \\ risks.
}

\section{On the available evidence, these treatments may be harmful}

\section{On the available evidence, these treatments do not seem to be effective.}

\section{These treatments have not been properly researched. It is not possible to say whether they are useful or not. It is unclear if the benefits outweigh the risks.}

\section{Step 8. Profession Descriptions}

In step 1, consumers had indicated confusion regarding the role of different health care providers. Descriptions were prepared for health care providers who manage back pain that have a registration board in Australia. Descriptions were prepared by the expert steering committee and consumer writer. These were refined and then approved by the professional associations that represent each discipline.

\section{Step 9. Development/Refinement of Algorithms to Guide Content Utilization}

A total of 2 algorithms were developed on the basis of existing stratification/prognostic tools to guide users of the website toward information that is tailored to their individual needs. The STarT Back tool [42] and Pick-up tool [43] were adapted to guide the user experience for individuals with LBP of greater than or less than 3 months duration, respectively. The STarT Back tool stratifies individuals with low, medium, and high risk for poor prognosis based on responses to 9 questions. The Pick-up tool calculates probability of good outcome based on responses to 5 questions. The tools were used to evaluate possible risk of poorer outcome and tailoring information regarding advice, particularly with respect to providing reassurance, and recommendations for access to psychologically informed resources were necessary. The "guide me" algorithm also included identification of red flags (eg, change in bladder and bowel function and perineal numbness) to trigger advice to seek medical consultation.

\section{Step 10. User Testing and Launch}

A full beta version of the website was constructed and extensively reviewed by consumers and experts. In-depth consumer input user testing was conducted with 10 individuals with LBP of different presentations and durations. Each consumer was observed as they interacted with the website and asked to voice what they were thinking as they moved through the site. This testing focused on both site content and functionality. A summary of feedback was recorded. Four experts who were not involved in development of the site were asked to provide detailed review of the website and written feedback. All feedback from the consumers and experts was discussed by the expert steering committee and postdoctoral fellow and addressed if appropriate. The site was launched on the July 30, 2019 [44]. The launch date was 12 months after the website was completed to ensure that the primary end point for a randomized controlled trial (RCT) of the impact of use of the website (see below) was not affected by control group participants inadvertently accessing the site. Figure 3 shows the landing page of the website. Multimedia Appendix 1 is a brief video that was prepared for people with LBP and clinicians who treat LBP to outline the purpose and content of the website. 
Figure 3. Screenshot of landing page for MyBackPain, an internet resource designed for people with low back pain to obtain information about their condition and guidance for managing/living with low back pain.

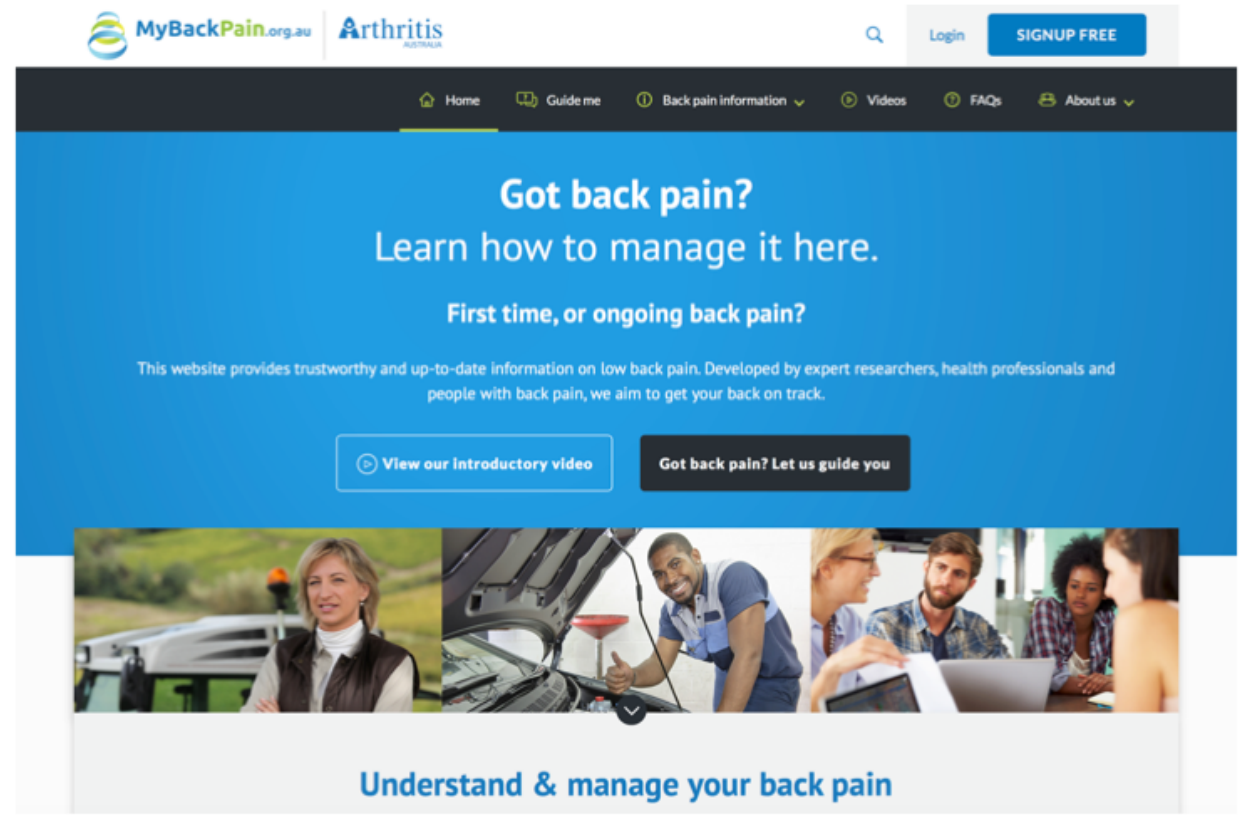

\section{Evaluation of MyBackPain}

\section{Evaluation 1: Randomized Controlled Trial of Impact of MyBackPain}

Before the launch of MyBackPain, an RCT was undertaken to investigate the effectiveness of the website in improving spinal health literacy, treatment preferences, and clinical outcomes for people with LBP, in comparison with other online resources. MyBackPain was made available by username/password access only during this period. The pragmatic trial was conducted online. Participants were 440 people with nonspecific LBP of any duration, stratified to those with LBP for a duration of greater than or less than 12 weeks. Participants, research staff, and the biostatistician were blinded to treatment allocation. Data were collected at baseline and 1, 3 (primary end point), 6, and 12 months via online surveys and questionnaires. The primary outcome measure was spinal health literacy measured using dimensions 2 and 3 ("having sufficient information to manage my health" and "actively managing my health") of the Health Literacy Questionnaire [45]. Participants are asked to consider their LBP when answering the survey. Secondary outcomes include the quality of treatment preferences (whether patients choose treatments that are supported by evidence) and LBP clinical outcomes (pain, disability, and quality of life). The trial has been prospectively registered (ACTRN12617001292369; registered on September 7, 2017). Long-term outcomes will be finalized in May 2020, with trial results available soon thereafter.

\section{Evaluation 2: Interdisciplinary, Postqualitative Evaluation of MyBackPain}

Although health websites provide information in a convenient format, they can be reductionist in their capacity to accommodate the complexities of human life, health, evidence, and the diverging philosophies underpinning different forms of health care. A postqualitative analysis of MyBackPain was undertaken by a team with backgrounds in public health, sociology, physiotherapy, psychology, and occupational therapy and an expert consumer with LBP (Setchell J, Olson R, Turpin M, Costa N, Barlott T, O'Halloran K, Wigginton B, Hodges P, unpublished data, February 2019). The analysis aimed to evaluate the success of the website at providing health information that was simultaneously scientifically rigorous and avoidant of associated pitfalls such as reduced consideration of complexity of the condition. The analysis was guided by Ahmed's theory [46] of the socioculturality of emotions and was designed to reflect on experiences as the team individually navigated the website, followed by team discussion. Through this postqualitative inquiry process, it was recognized that some forms of communication used in the website had the potential to marginalize some users (eg, although images showed individuals of diverse background, all were happy and undertaking productive activities, which may marginalize users who do not identify with those images, and evidence for treatment was limited to RCTs - although this is conventionally used in most evaluations of treatment efficacy, other forms of evidence [eg, qualitative interpretations] can contribute and can be desired by users) but liberated possibilities of others (eg, videos presented real stories by real people). Caution was identified regarding the assumption that consumer education and choice enhance consumer health and the potential unintended negative effects of the focus on changing individual behaviors, particularly lifestyle factors such as activity and exercise, which can lead to feelings of guilt when this cannot be achieved and shame that they are somehow responsible for their LBP. Each of these issues can be addressed though refinement of website messaging and explicit recognition within the website to acknowledge the issues. 


\section{Evaluation 3: Qualitative Analysis of People's Interactions With the Website and Its Effects in Their Daily Lives}

A qualitative study was undertaken using methods adapted from discourse analysis to identify potential tensions in the website content (Setchell J, Turpin M, Costa N, Hodges P, unpublished data October 2019). Participants with LBP were observed while interacting with the website and asked to discuss their responses. For 1 month before a follow-up interview, these participants took photographs of what was happening in their lives when they thought of the website. Photographs were used to prompt discussion. A postcritical discourse analysis approach identified 4 areas of tension in the presentation of material on the website: (1) the website focused on reducing LBP, with little discussion of living with LBP, which may be the goal or the reality for some individuals; (2) the website tended toward discussion of keeping active and not resting, potentially leading to feelings of guilt if activity targets could not be met; (3) there was tension between educating people with LBP to make their own choice vs providing explicit guidance, with the desired balance between these depending on the individual user; and (4) although the treatment summaries intend to inform users of evidence-based treatments to guide choices, this information had an unintended negative impact on some participants who had used disproven or potentially harmful treatments. These tensions were unanticipated in the design of the website and will be addressed by explicit recognition and discussion of these tensions in multiple formats (eg, videos and pop-up boxes at appropriate locations of the site where tensions arise).

\section{Plan for Review and Revision of MyBackPain}

As information regarding LBP (particularly treatments) evolves with future research, there will be a need to review and update the content of the website. A governance structure has been established to overview regular review and revision of the content. The website uses a content management system with concurrent possibilities for updating much of the content. Critically, the content of the treatment summaries will be updated at least biannually with the guidance of the international advisors who contributed to their development (and others, as appropriate). New content is planned and contingent upon future funding.

\section{Discussion}

This paper describes the multistep process undertaken to develop a website for people with LBP to meet their expressed needs for content and presentation. The rigorous process used to develop this resource is rare, and we hope that outlining the iterative steps we undertook might help others to develop resources for consumers. A major component of the process was extensive involvement of consumers in defining the content, providing feedback on the content, and evaluating the final website. A multidisciplinary group of international experts were recruited to guide development of the website and provide input/review of content at many steps. Most steps involved in the development of the website were undertaken in a formal manner with publication and presentation of the results in academic literature.

MyBackPain was designed to address the issue that most available resources do not meet the expressed needs of people with LBP [38] and use language that is not optimized for users to understand [23]. It has also been identified that websites for LBP generally provide inaccurate information and do not consider the spectrum of presentations of LBP [21], another key objective of the development of MyBackPain.

It is hoped that MyBackPain will provide a useful resource for people with LBP and their friends and families. We also hope that health care providers will derive benefit from referring patients to the website for reinforcement of key messages and to generate a partnership in decision making for treatment. Ultimately, the intention of the website is to contribute to reducing the massive burden of LBP. The extensive process of development and consumer/expert engagement that we have undertaken could also provide a template for the development of resources for other conditions.

\section{Acknowledgments}

Funding for development of MyBackPain was provided by the National Health and Medical Research Council of Australia (Centre of Research Excellence grant [APP1079078], program grant [APP1091302], and fellowship [APP1102905]). Medibank Better Health Fund contributed funding for the RCT. Arthritis Australia funded the qualitative evaluation. The authors would like to thank Prof Maurits van Tulder, Prof Chris Maher, and Dr Simon French who were part of the steering committee. The authors would also like to thank Prof Jan Hartvigsen, Dr Steve Kamper, Mark Schoene, Prof Nadine Foster, Terry Corbin, and Dr Paul Campbell who were part of the external advisory committee. The authors would like to thank the following experts who advised on the content in the treatment summaries: Dr Britt Stuge, Dr Andrea Furlan, Prof Bart Koes, Bruno Saragiotto, Dr Bart Staal, Prof Chris Maher, Dr Christina Shaheed, Prof David Baxter, Donna Urquhart, Dr Emma Irvin, Dr Esther Maas, Dr Venerina Johnston, Dr Frederiecke Schaafsma, Dr Gro Jamtvedt, Dr Ian Harris, Dr Joel Gagnier, Dr José Guerts, Dr Jan Hartvigsen, Dr Jill Hayden, Dr Jos Verbeek, Dr Lucie Brusseau, Dr Lixing Lao, Dr Luciana Machado, Dr Lisa Wieland, Dr Mark Arts, Dr Manuela Ferreira, Dr Martijn Heymans, Prof Maurits van Tulder, Dr Nicholas Henschke, Dr Paul Little, Dr Pepijn Roelofs, Dr Roger Chou, Dr Richard Deyo, Dr Raymond Ostelo, Dr Rob Smeets, Dr Steven Cohen, Dr Simon Dagenais, Dr Simon French, Dr Steven Kamper, Dr Sidney Rubenstein, Dr Tom Bendix, Dr Teddy Oosterhuis, Dr Tie Yamato, and Dr Paulo Ferreira. The authors emphatically thank the consumers, clinicians, and experts who gave input throughout the process of website development.

\section{Conflicts of Interest}

None declared. 


\section{Multimedia Appendix 1}

Explanatory video for MyBackPain: introduction to purpose and features of the website. [MP4 File (MP4 Video), 189910 KB-Multimedia Appendix 1]

\section{References}

1. GBD 2017 Disease Injury Incidence Prevalence Collaborators. Global, regional, and national incidence, prevalence, and years lived with disability for 354 diseases and injuries for 195 countries and territories, 1990-2017: a systematic analysis for the Global Burden of Disease Study 2017. Lancet 2018 Nov 10;392(10159):1789-1858 [FREE Full text] [doi: 10.1016/S0140-6736(18)32279-7] [Medline: 30496104]

2. Henderson JV, Harrison CM, Britt HC, Bayram CF, Miller GC. Prevalence, causes, severity, impact, and management of chronic pain in Australian general practice patients. Pain Med 2013 Sep;14(9):1346-1361. [doi: 10.1111/pme.12195] [Medline: 23855874]

3. Australian Institute of Health and Welfare. Australia's Health 2006. Canberra: Australian Institute of Health and Welfare; 2006.

4. Williams CM, Maher CG, Hancock MJ, McAuley JH, McLachlan AJ, Britt H, et al. Low back pain and best practice care: a survey of general practice physicians. Arch Intern Med 2010 Feb 8;170(3):271-277. [doi: 10.1001/archinternmed.2009.507] [Medline: 20142573]

5. Darlow B, Dowell A, Baxter GD, Mathieson F, Perry M, Dean S. The enduring impact of what clinicians say to people with low back pain. Ann Fam Med 2013;11(6):527-534 [FREE Full text] [doi: 10.1370/afm.1518] [Medline: 24218376]

6. Buchbinder R, Jolley D, Wyatt M. Population based intervention to change back pain beliefs and disability: three part evaluation. Br Med J 2001 Jun 23;322(7301):1516-1520 [FREE Full text] [doi: 10.1136/bmj.322.7301.1516] [Medline: 11420272]

7. George SZ, Teyhen DS, Wu SS, Wright AC, Dugan JL, Yang G, et al. Psychosocial education improves low back pain beliefs: results from a cluster randomized clinical trial (NCT00373009) in a primary prevention setting. Eur Spine J 2009 Jul;18(7):1050-1058 [FREE Full text] [doi: 10.1007/s00586-009-1016-7] [Medline: 19418075]

8. Bloem BR, Munneke M. Revolutionising management of chronic disease: the ParkinsonNet approach. Br Med J 2014 Mar 19;348:g1838. [doi: 10.1136/bmj.g1838] [Medline: 24647365]

9. Kummervold PE, Chronaki CE, Lausen B, Prokosch H, Rasmussen J, Santana S, et al. eHealth trends in Europe 2005-2007: a population-based survey. J Med Internet Res 2008 Nov 17;10(4):e42 [FREE Full text] [doi: 10.2196/jmir.1023] [Medline: 19017584]

10. Fox S. Pew Internet Research. 2009 Jun 11. The Social Life of Health Information URL: https://www.pewresearch.org/ internet/2009/06/11/the-social-life-of-health-information/ [accessed 2019-09-03]

11. Brown CA. The beliefs of people with chronic pain in relation to 'important' treatment components. Eur J Pain 2004 Aug;8(4):325-333. [doi: 10.1016/j.ejpain.2003.10.005] [Medline: 15207513]

12. Dewar A, White M, Posade ST, Dillon W. Using nominal group technique to assess chronic pain, patients' perceived challenges and needs in a community health region. Health Expect 2003 Mar;6(1):44-52 [FREE Full text] [doi: 10.1046/j.1369-6513.2003.00208.x] [Medline: 12603627]

13. Glenton C. Developing patient-centred information for back pain sufferers. Health Expect 2002 Dec;5(4):319-329 [FREE Full text] [doi: $\underline{10.1046 / j .1369-6513.2002 .00196 . x}$ ] [Medline: $\underline{12460221}$ ]

14. Laerum E, Indahl A, Skouen JS. What is 'the good back-consultation'? A combined qualitative and quantitative study of chronic low back pain patients' interaction with and perceptions of consultations with specialists. J Rehabil Med 2006 Jul;38(4):255-262 [FREE Full text] [doi: 10.1080/16501970600613461] [Medline: 16801209]

15. McIntosh A, Shaw CFM. Barriers to patient information provision in primary care: patients' and general practitioners' experiences and expectations of information for low back pain. Health Expect 2003 Mar;6(1):19-29 [FREE Full text] [doi: 10.1046/j.1369-6513.2003.00197.x] [Medline: 12603625$]$

16. Wald HS, Dube CE, Anthony DC. Untangling the web--the impact of internet use on health care and the physician-patient relationship. Patient Educ Couns 2007 Nov;68(3):218-224. [doi: 10.1016/j.pec.2007.05.016] [Medline: 17920226]

17. Ahmad F, Hudak PL, Bercovitz K, Hollenberg E, Levinson W. Are physicians ready for patients with internet-based health information? J Med Internet Res 2006 Sep 29;8(3):e22 [FREE Full text] [doi: 10.2196/jmir.8.3.e22] [Medline: 17032638]

18. Eysenbach G, Diepgen TL. Towards quality management of medical information on the internet: evaluation, labelling, and filtering of information. Br Med J 1998 Nov 28;317(7171):1496-1500 [FREE Full text] [doi: 10.1136/bmj.317.7171.1496] [Medline: 9831581$]$

19. Gerber BS, Eiser AR. The patient physician relationship in the Internet age: future prospects and the research agenda. $\mathrm{J}$ Med Internet Res 2001;3(2):E15 [FREE Full text] [doi: 10.2196/jmir.3.2.e15] [Medline: 11720957]

20. Murray E, Lo B, Pollack L, Donelan K, Catania J, Lee K, et al. The impact of health information on the internet on health care and the physician-patient relationship: national U.S. survey among 1.050 US physicians. J Med Internet Res 2003;5(3):e17 [FREE Full text] [doi: 10.2196/jmir.5.3.e17] [Medline: 14517108] 
21. Ferreira G, Traeger AC, Machado G, O'Keeffe M, Maher CG. Credibility, Accuracy, and Comprehensiveness of Internet-Based Information About Low Back Pain: A Systematic Review. J Med Internet Res 2019 May 7;21(5):e13357 [FREE Full text] [doi: $\underline{10.2196 / 13357]}$ [Medline: $\underline{\text { 31066689] }}$

22. Butler L, Foster NE. Back pain online: a cross-sectional survey of the quality of web-based information on low back pain. Spine (Phila Pa 1976) 2003 Feb 15;28(4):395-401. [doi: 10.1097/01.BRS.0000048497.38319.D3] [Medline: 12590218]

23. Hendrick PA, Ahmed OH, Bankier SS, Chan TJ, Crawford SA, Ryder CR, et al. Acute low back pain information online: an evaluation of quality, content accuracy and readability of related websites. Man Ther 2012 Aug;17(4):318-324. [doi: 10.1016/j.math.2012.02.019] [Medline: 22464886]

24. Li L, Irvin E, Guzmán J, Bombardier C. Surfing for back pain patients: the nature and quality of back pain information on the internet. Spine (Phila Pa 1976) 2001 Mar 1;26(5):545-557. [doi: 10.1097/00007632-200103010-00020] [Medline: 11242383]

25. Mathur S, Shanti N, Brkaric M, Sood V, Kubeck J, Paulino C, et al. Surfing for scoliosis: the quality of information available on the internet. Spine (Phila Pa 1976) 2005 Dec 1;30(23):2695-2700. [doi: 10.1097/01.brs.0000188266.22041.c2] [Medline: 16319757]

26. Gremeaux V, Coudeyre E, Givron P, Hérisson C, Pélissier J, Poiraudeau S, et al. Qualitative evaluation of the expectations of low back pain patients with regard to information gained through semi-directed navigation on the internet. Ann Readapt Med Phys 2007 Jul;50(6):348-55, 339. [doi: 10.1016/j.annrmp.2007.03.017] [Medline: 17513002]

27. Greene DL, Appel AJ, Reinert SE, Palumbo MA. Lumbar disc herniation: evaluation of information on the internet. Spine (Phila Pa 1976) 2005 Apr 1;30(7):826-829. [doi: 10.1097/01.brs.0000157754.98023.cd] [Medline: 15803087]

28. Krahn M, Naglie G. The next step in guideline development: incorporating patient preferences. J Am Med Assoc 2008 Jul 23;300(4):436-438. [doi: 10.1001/jama.300.4.436] [Medline: 18647988]

29. World Health Organization. Geneva: World Health Organisation; 2015. WHO Global Strategy on People-Centred and Integrated Health Services: Interim Report URL: https://apps.who.int/iris/handle/10665/155002 [accessed 2019-09-03]

30. Nilsen ES, Myrhaug HT, Johansen M, Oliver S, Oxman AD. Methods of consumer involvement in developing healthcare policy and research, clinical practice guidelines and patient information material. Cochrane Database Syst Rev 2006 Jul 19(3):CD004563 [FREE Full text] [doi: 10.1002/14651858.CD004563.pub2] [Medline: 16856050]

31. Pain Australia. 2010. National Pain Strategy URL: https://www.painaustralia.org.au/static/uploads/files/ national-pain-strategy-2011-wfvjawttsanq.pdf [accessed 2019-09-03]

32. Pain Australia. 2014 May. Review of progress with the National Pain Strategy URL: https://www.painaustralia.org.au/ static/uploads/files/draft-progress-review-pdf-29-may-wfshjgzzvhqf.pdf [accessed 2019-09-03]

33. Bailey SJ, LaChapelle DL, LeFort SM, Gordon A, Hadjistavropoulos T. Evaluation of chronic pain-related information available to consumers on the internet. Pain Med 2013 Jun;14(6):855-864. [doi: 10.1111/pme.12087] [Medline: 23565667]

34. Galbusera F, Brayda-Bruno M, Freutel M, Seitz A, Steiner M, Wehrle E, et al. What do patients know about their low back pain? An analysis of the quality of information available on the Internet. Technol Health Care 2012;20(6):447-455. [doi: 10.3233/THC-2012-0682] [Medline: 23187011]

35. Nielsen M, Jull G, Hodges PW. Information needs of people with low back pain for an online resource: a qualitative study of consumer views. Disabil Rehabil 2014;36(13):1085-1091. [doi: 10.3109/09638288.2013.829532] [Medline: 24001260]

36. Nielsen M, Jull G, Hodges PW. Designing an online resource for people with low back pain: health-care provider perspectives. Aust J Prim Health 2016;22(2):159-166. [doi: 10.1071/PY14131] [Medline: 25705821]

37. Plinsinga ML, Besomi M, Maclachlan L, Melo L, Robbins S, Lawford BJ, et al. Exploring the characteristics and preferences for online support groups: mixed method study. J Med Internet Res 2019 Dec 3;21(12):e15987 [FREE Full text] [doi: 10.2196/15987] [Medline: 31793893 ]

38. Costa N, Nielsen M, Jull G, Claus AP, Hodges PW. Low back pain websites do not meet the needs of consumers: a study of online resources at three time points. Health Inf Manag 2019 Jul 2:1833358319857354. [doi: 10.1177/1833358319857354] [Medline: $\underline{31266366}$ ]

39. French SD, Nielsen M, Hall L, Nicolson PJ, van Tulder M, Bennell KL, et al. Essential key messages about diagnosis, imaging, and self-care for people with low back pain: a modified Delphi study of consumer and expert opinions. Pain 2019 Dec;160(12):2787-2797. [doi: 10.1097/j.pain.0000000000001663] [Medline: 31356451]

40. Koes BW, van Tulder M, Lin CC, Macedo LG, McAuley J, Maher C. An updated overview of clinical guidelines for the management of non-specific low back pain in primary care. Eur Spine J 2010 Dec;19(12):2075-2094 [FREE Full text] [doi: 10.1007/s00586-010-1502-y] [Medline: 20602122]

41. Graves JM, Fulton-Kehoe D, Jarvik JG, Franklin GM. Early imaging for acute low back pain: one-year health and disability outcomes among Washington State workers. Spine (Phila Pa 1976) 2012 Aug 15;37(18):1617-1627. [doi: 10.1097/BRS.0b013e318251887b] [Medline: 22415000]

42. Hill JC, Dunn KM, Lewis M, Mullis R, Main CJ, Foster NE, et al. A primary care back pain screening tool: identifying patient subgroups for initial treatment. Arthritis Rheum 2008 May 15;59(5):632-641 [FREE Full text] [doi: 10.1002/art.23563] [Medline: 18438893] 
43. Traeger AC, Henschke N, Hübscher M, Williams CM, Kamper SJ, Maher CG, et al. Estimating the Risk of Chronic Pain: Development and Validation of a Prognostic Model (PICKUP) for Patients with Acute Low Back Pain. PLoS Med 2016 May;13(5):e1002019 [FREE Full text] [doi: 10.1371/journal.pmed.1002019] [Medline: 27187782]

44. MyBackPain. URL: https://MyBackPain.org.au [accessed 2019-09-03]

45. Osborne RH, Batterham RW, Elsworth GR, Hawkins M, Buchbinder R. The grounded psychometric development and initial validation of the Health Literacy Questionnaire (HLQ). BMC Public Health 2013 Jul 16;13:658 [FREE Full text] [doi: 10.1186/1471-2458-13-658] [Medline: 23855504]

46. Ahmed S. The Cultural Politics of Emotion. Edinburgh, United Kingdom: Edinburgh University Press; 2014.

\section{Abbreviations \\ FAQs: frequently asked questions \\ LBP: low back pain \\ RCT: randomized controlled trial}

Edited by G Eysenbach; submitted 02.09.19; peer-reviewed by E Sadeghi-Demneh, N Ansari; comments to author 02.11.19; accepted 15.12.19; published 31.03.20

Please cite as:

Hodges PW, Setchell J, Nielsen $M$

An Internet-Based Consumer Resource for People with Low Back Pain (MyBackPain): Development and Evaluation

JMIR Rehabil Assist Technol 2020;7(1):e16101

URL: http://rehab.jmir.org/2020/1/e16101/

doi: $\underline{10.2196 / 16101}$

PMID: 32229467

CPaul William William Hodges, Jenny Setchell, Mandy Nielsen. Originally published in JMIR Rehabilitation and Assistive Technology (http://rehab.jmir.org), 31.03.2020. This is an open-access article distributed under the terms of the Creative Commons Attribution License (https://creativecommons.org/licenses/by/4.0/), which permits unrestricted use, distribution, and reproduction in any medium, provided the original work, first published in JMIR Rehabilitation and Assistive Technology, is properly cited. The complete bibliographic information, a link to the original publication on http://rehab.jmir.org/, as well as this copyright and license information must be included. 